\title{
Controllable Impregnation via Inkjet Printing for the Fabrication of Solid Oxide Cell Air Electrodes
}

\author{
Eman Husni Da' as ${ }^{\mathrm{a}}$, John T. S. Irvine ${ }^{\mathrm{b}}$, Enrico Traversa ${ }^{\mathrm{a}}$, Samir Boulfrad $^{\mathrm{a}}$ \\ ${ }^{a}$ Division of Physical Sciences and Engineering \\ King Abdullah University of Science and Technology-KAUST, Thuwal 4700, KSA \\ ${ }^{\mathrm{b}}$ School of Chemistry, University of St. Andrews, Scotland, UK
}

The impregnation method has been considered as one of the most successful techniques for the fabrication of highly efficient electrodes for solid oxide fuel and electrolysis cells (SOCs) at the lab scale. However, because the impregnation is usually performed manually, its irreproducibility remains a major problem that can be solved by using controllable techniques, such as inkjet printing. In this paper, lanthanum strontium manganite (LSM)/yttria stabilized zirconia (YSZ) air electrodes were prepared by infiltrating YSZ porous bodies with LSM precursor solution using inkjet printing, followed by annealing at $800^{\circ} \mathrm{C}$ for 2 hours. XRD analysis confirmed the formation of the LSM phase, which was in the form of nanoparticles with size in the 50-70 $\mathrm{nm}$ range on the YSZ walls, as revealed by FEG-SEM observations. The effect of printing parameters on the distribution of the impregnated phase was investigated and is discussed.

\section{Introduction}

Solid oxide fuel cells (SOFCs) are high temperature electrochemical devices that efficiently convert the chemical energy of a fuel into clean power (1). On the other hand, solid oxide electrolysis cells (SOECs), which are SOFCs operating in reverse, are high temperature energy storage devices that convert heat and electrical power into chemical energy by producing hydrogen from steam (2). Both types share similar structures, materials and manufacturing processes (3). The state-of-the-art materials for SOCs devices are $\mathrm{Ni} /$ yttria stabilized zirconia (YSZ) for the fuel electrode, YSZ for the electrolyte, and lanthanum strontium manganite (LSM)/YSZ for the air electrode $(4,5)$.

As a drawback, the high operating temperatures $\left(800-1000^{\circ} \mathrm{C}\right)$ limit the cell lifetime and the choice of cost-effective materials (6). Operating SOFCs in the intermediate temperature (IT) range increases the stability of the cells, shortens the startup time, and offers a variety of cheaper materials. However, reducing the operating temperature influences the electrochemical performance of SOCs (7) by increasing the polarization resistance at the electrodes $(8,9)$. To overcome this problem, two approaches have been investigated: the use of alternative materials for air electrodes (10-13) and the improvement of the electrode microstructure $(14,15)$.

Better electrode microstructure can be achieved by increasing the length of the triple phase boundaries (TPB), which results in smaller polarization resistance $(16,17)$. This 
can be attained through liquid impregnation of nanostructured electrocatalytic materials, or precursors of active materials, into pre-sintered porous backbone structures. The solution concentration and the number of infiltration cycles control the effectiveness of the impregnation process $(18,19)$. Nevertheless, the impregnation methods commonly reported in the literature at the lab scale are performed manually using micro-pipettes and syringes (20), or by dip coating (21). This leads to reproducibility and scalability issues, in addition to contamination of non-relevant areas in the cell and materials waste. Consequently, this barrier has to be overcome in order to allow industrial development.

In this work we propose piezoelectric drop-on-demand (DOD) inkjet printing as a scalable and industry-compatible technology to perform impregnation for SOC applications. Thus, the infiltration process of a pre-sintered porous-YSZ backbone structure with LSM nitrate aqueous solutions was investigated using inkjet printing, to control the lateral dispersion and the depth penetration of the solution inside the porousYSZ substrates.

Inkjet printing has been reported as an effective, simple and low-cost fabrication and deposition technique to control patterning and to form 2D or 3D structures (22). Piezoelectric DOD inkjet printing is based on the use of ceramic piezoactuators that expand or shrink upon the applied voltage direction. The piezoceramics, usually made of lead zirconate titanate (PZT), are located on the ink chamber walls. Applying voltage to the actuator generates enough pressure on the ink to come out of the nozzle. Controlling the actuator volume changes through controlling the applied voltage insures the easy control of the drop size and its velocity. Piezoelectric DOD inkjet printing offers high resolution, less wasting of materials, and printing ability in ambient conditions (23).

\section{Experimental Procedure}

Approximately $95 \mu \mathrm{m}$-thick porous YSZ substrates were manufactured after sintering a tape-cast mixture of YSZ and pore former at $1400^{\circ} \mathrm{C}$ for $2 \mathrm{~h}$. The LSM solution for inkjet-impregnation was prepared by dissolving $\mathrm{La}\left(\mathrm{NO}_{3}\right)_{3} \cdot 6 \mathrm{H}_{2} \mathrm{O}, \mathrm{Sr}\left(\mathrm{NO}_{3}\right)_{2}$, and $\mathrm{Mn}\left(\mathrm{NO}_{3}\right)_{2} \cdot 4 \mathrm{H}_{2} \mathrm{O}$ in deionized water.

A DMP-2800 inkjet printer from Fujifilm Dimatix was used to perform inkjet printing. The LSM ink was filled in cartridges allowing $10 \mathrm{pL}$ drop size. Each cartridge contained 16 nozzles, with diameter $<15 \mu \mathrm{m}$, aligned in a single line spaced by $254 \mu \mathrm{m}$.

The optimization of inkjet impregnation was achieved by printing " $\mathrm{H}$ "-shaped patterns, with digital input dimensions $\left(\mathrm{i}_{0}\right)$ as shown in Figure 1. The printing process was performed using different parameters to investigate their influence on the lateral dispersion of the printed ink, with respect to the " $\mathrm{H}$ " pattern digital input dimensions. Therefore, porous YSZ substrates placed on the printer plate were heated to different temperatures $\left(30,40,50\right.$ and $\left.60^{\circ} \mathrm{C}\right)$. The drop spacing was varied at 10,15 , and $20 \mu \mathrm{m}$. The number of the printed layers was 4 and 8 . The cartridge height, defined as the distance between the substrate and the print-head, was varied at $0.25,0.5$, and $0.75 \mathrm{~mm}$. After printing, all the samples were dried at $100^{\circ} \mathrm{C}$ and then fired at $800^{\circ} \mathrm{C}$ for $2 \mathrm{~h}$ with a $2^{\circ} \mathrm{C} / \mathrm{min}$ heating rate, to get the required nanostructured LSM phase. 


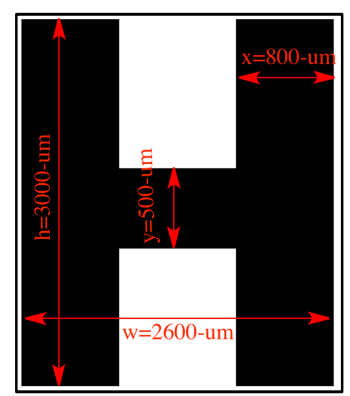

Figure 1. "H"-shaped pattern with $\mathrm{i}_{0}\left(\mathrm{i}_{0}=\mathrm{w}, \mathrm{h}, \mathrm{x}\right.$, or $\left.\mathrm{y}\right)$ dimensions in $\mu \mathrm{m}$.

The lateral dispersion for the inkjet-impregnated substrates was studied using an optical microscope. The morphology and the microstructure of the layers were investigated using a scanning electron microscope (SEM). X-ray diffraction (XRD) analysis was used to confirm the formation of the LSM perovskite phase.

\section{Results and Discussion}

The printed nitrate solution ink is colorless, thus the pattern cannot be seen just after printing. A brownish color started to appear with drying, indicating some decomposition of the nitrate salts. Dark color patterns were observed after annealing at $800^{\circ} \mathrm{C}$, as shown in Figure 2, suggesting the LSM phase formation. From optical microscopy and naked eye observations, the " $H$ " pattern shape and the lateral dispersion of the ink in the porous substrates depend strongly on the printing parameters, as will be discussed later.

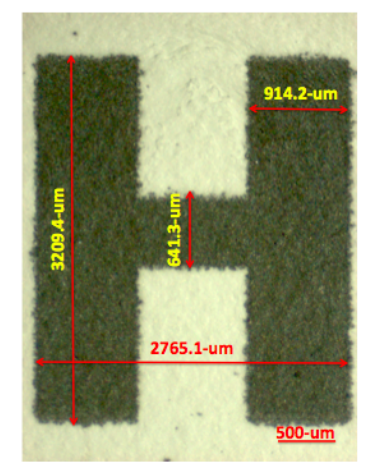

Figure 2. A typical optical microscope image of the inkjet-impregnated sample after sintering.

\section{Structural and Morphological Analysis}

XRD analysis confirmed the formation of $\mathrm{La}_{0.8} \mathrm{Sr}_{0.2} \mathrm{MnO}_{3}$ (LSM) phase (Figure 3). The main LSM peak appears at $32.24^{\circ}$. LSM usually presents peaks with lower intensity comparatively to YSZ even with equal ratio of the two materials. In our samples, the amount of LSM is relatively smaller than YSZ. In addition, as confirmed by SEM, the LSM was formed as nanostructured particles, which made the XRD peaks broad, and thus making even harder to distinguish them. 


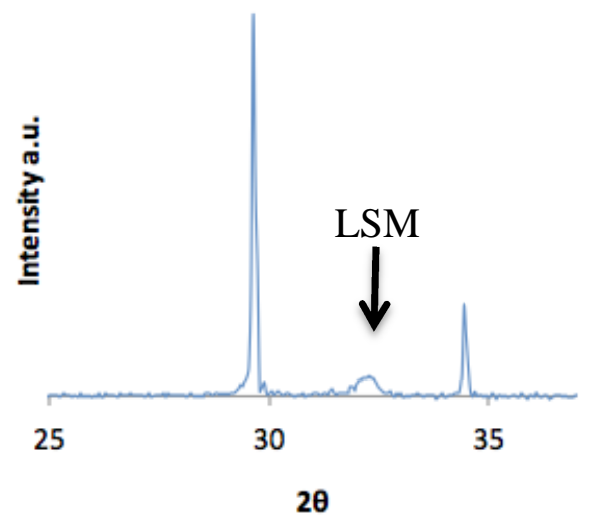

Figure 3. XRD plot of LSM inkjet-impregnated onto porous YSZ after annealing at $800^{\circ} \mathrm{C}$.

The SEM characterization (Figure 4) shows the morphology of LSM coated on porous YSZ substrates by inkjet impregnation. Despite what one could expect due to the high surface tension of water, homogenous wettability of LSM on porous YSZ walls achieved homogeneous distribution of LSM nanostructured particles. As expected from the impregnation technique followed by low temperature annealing (24), the LSM coating exhibited a very fine microstructure with particles in the 50-70 $\mathrm{nm}$ range.

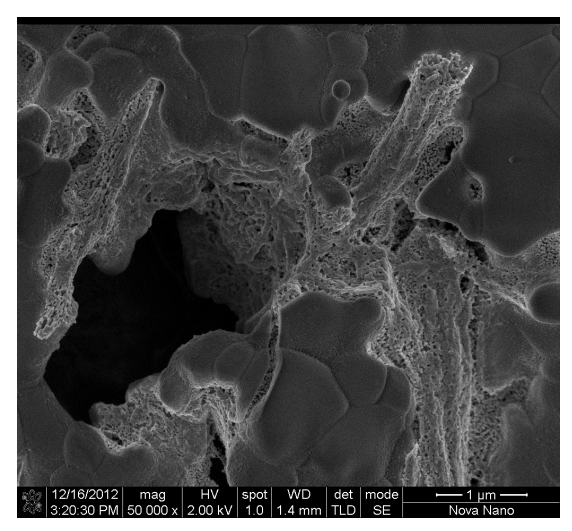

Figure 4. SEM micrograph of LSM nanoparticles coating the YSZ porous substrate, after impregnation and sintering, obtained with 4 layers inkjet impregnation.

\section{Effect of Printing Parameters}

The lateral dispersion after printing was determined comparing optical microscopy observations, like in Figure 2, with the dimensions of the digital input $\left(\mathrm{i}_{0}\right)$ as in Figure 1. The relative lateral dispersion was defined using a dimensionless number $\mathrm{i} \%$ as:

$$
\mathrm{i} \%=100 * \Delta \mathrm{i} / \mathrm{i}_{0}
$$

where $\mathrm{i}_{0}$ represents the digital input dimensions ( $\mathrm{w}, \mathrm{h}, \mathrm{x}$, or $\mathrm{y}$ in $\left.\mu \mathrm{m}\right)$ of the " $\mathrm{H}$ " pattern, as in Figure 1, $\Delta \mathrm{i}$ is defined as the difference between the dimensions of the " $\mathrm{H}$ " pattern after printing and annealing $\left(i_{p}\right)$, as in Figure 2 , and $i_{0}$. 


$$
\Delta \mathrm{i}=\mathrm{i}_{\mathrm{p}}-\mathrm{i}_{0}
$$

Figure 5 shows the effect of printing parameters on the relative lateral dispersion "i\%". From a general observation, one can state that printing shapes with smaller dimensions $(\mathrm{x}, \mathrm{y})$ induced larger $\mathrm{i} \%$ than in the case of larger dimensions $(\mathrm{h}, \mathrm{w})$. This might be due to the fact that the lateral dispersion of one single drop would have higher impact in the case of patterns with smaller dimensions.

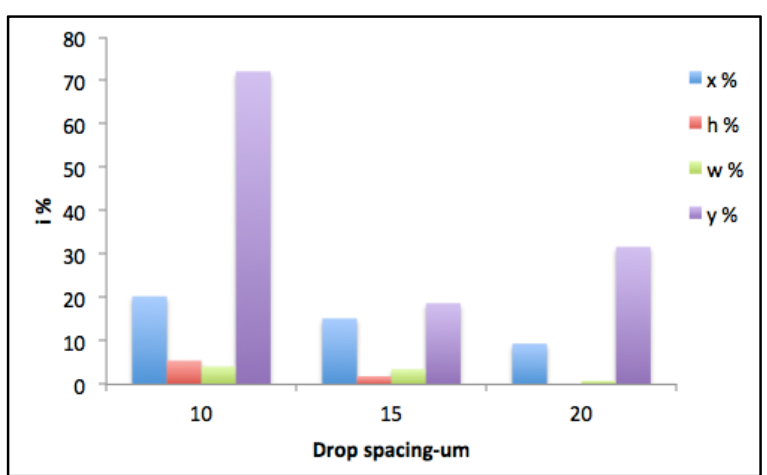

(a)

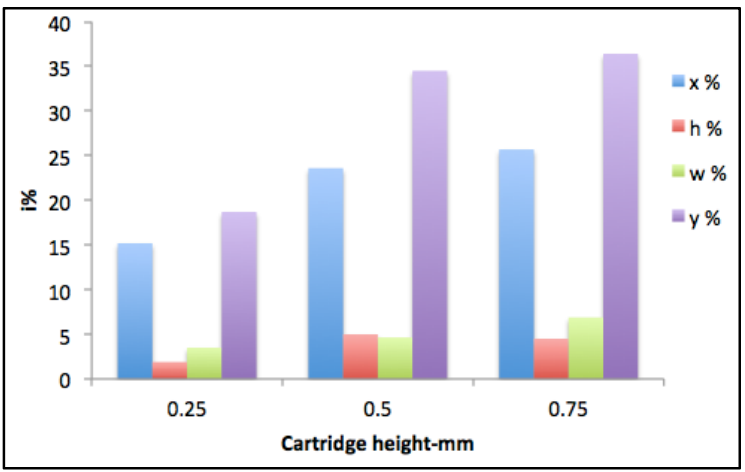

(c)

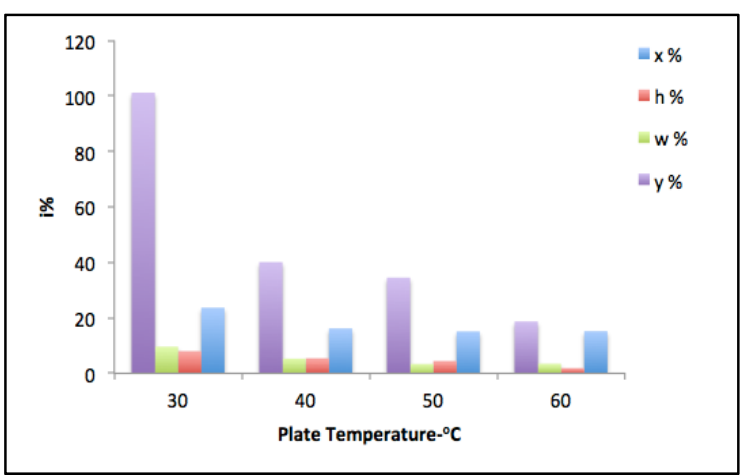

(b)

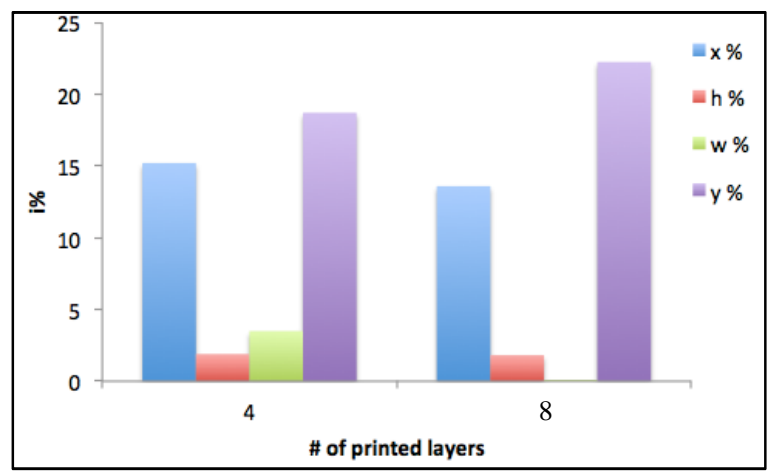

(d)

Figure 5. Effect of printing parameters on the relative lateral dispersion i\%: (a) drop spacing, (b) plate temperature, (c) cartridge height, (d) number of layers.

Figure 5(a) shows the effect of the drop spacing on i\%. Three values were investigated, i.e. 10,15 , and $20 \mu \mathrm{m}$. The other printing parameters were fixed as: four printed layers, cartridge height relatively to the substrate of $0.25 \mathrm{~mm}$, and $60^{\circ} \mathrm{C}$ as the substrate temperature. From Figure 5(a), one can notice that the best results are obtained with 15 and $20 \mu \mathrm{m}$ drop spacing. However, $15 \mu \mathrm{m}$ is preferable because it allows larger amounts of LSM to be infiltrated, approximately double than for the $20 \mu \mathrm{m}$ case. The effect of substrate temperature was investigated while the other parameters were fixed as: four printed layers, $15 \mu \mathrm{m}$ drop spacing, and $0.25 \mathrm{~mm}$ cartridge height. As expected, the results indicated that the lower the substrate temperature, the larger the relative lateral dispersion, as shown in Figure 5(b). In the case of $30^{\circ} \mathrm{C}$, the obtained pattern shape was hardly reproducible, indicating a very low level of control of the printed ink diffusion inside the porous substrate. Therefore, the plate temperature was fixed at $60^{\circ} \mathrm{C}$. Better printing control was obtained with smaller values of the cartridge height, as presented in Figure 5(c). The drop falling velocity increased with larger height values, which might cause splashing and increase the spreading diameter of the drop on the substrate. With the 
above parameters having been optimized, the effect of the number of printed layers was investigated by comparing i\% in samples with 4 and 8 printed layers (Figure 5(d)). Whilst slightly better results were obtained with 4 layers, the dispersion control is still acceptable with a larger number of printed layers, especially when using the other optimized printing parameters. This finding is important because it makes possible to control the dispersion of the impregnated material even when large amounts are required.

In general, good control of the impregnation process through inkjet printing requires a good balance between the volume of the ink introduced into the porous media and the evaporation rate of the solvent in the ink. In our experimental conditions, the optimum printing parameters were defined as: $15 \mu \mathrm{m}$ drop spacing, $60^{\circ} \mathrm{C}$ plate temperature, and $0.25 \mathrm{~mm}$ cartridge height. The optimum parameters can be different depending on the morphology and the porosity of the substrate, and also on the properties of the printing ink, including the nature of solvent and salts, the viscosity, and the surface tension.

\section{Conclusions}

Inkjet printing has been successfully implemented in the impregnation process for the fabrication of SOC electrodes. The lateral dispersion of the impregnated material, LSM, was controlled through optimizing the printing parameters. Moreover, it was confirmed that impregnating complex shape patterns onto porous YSZ substrate is feasible and controllable. Thus, inkjet printing is an effective technique and a promising tool for the industrialization of impregnation process for large scale fabrication of SOC electrodes.

\section{References}

1. X. J. Liu, X. Meng, D. Han, H. Wu, F. R. Zeng and Z. L. Zhan, J Power Sources, 222, 92 (2013).

2. G. Tsekouras, D. Neagu and J. T. S. Irvine, Energ Environ Sci, 6, 256 (2013).

3. J. Kim, H. I. Ji, H. P. Dasari, D. Shin, H. Song, J. H. Lee, B. K. Kim, H. J. Je, H. W. Lee and K. J. Yoon, Int J Hydrogen Energ, 38, 1225 (2013).

4. P. Hjalmarsson, X. F. Sun, Y. L. Liu and M. Chen, J Power Sources, 223, 349 (2013).

5. J. C. Lin, F. P. Ting, T. Y. Lee, S. D. Chyou and C. M. Lai, Int J Hydrogen Energ, 38, 1714 (2013).

6. L. Almar, B. Colldeforns, L. Yedra, S. Estrade, F. Peiro, A. Morata, T. Andreua and A. Tarancon, J Mater Chem A, 1, 4531 (2013).

7. Y. M. Park and H. Kim, Ceram Int, 39, 2037 (2013).

8. Z. Liu, M. F. Liu, L. F. Nie and M. L. Liu, Int J Hydrogen Energ, 38, 1082 (2013).

9. Y. Chen, J. Bunch, C. Jin, C. H. Yang and F. L. Chen, J Power Sources, 204, 40 (2012).

10. A. E. Martinelli, D. A. Macedo, M. R. Cesario, B. Cela, J. P. Nicodemo, C. A. Paskocimas, D. M. A. Melo and R. M. Nascimento, Advanced Materials Forum Vi, Pts 1 and 2, 730-732, 147 (2013).

11. M. Andersson, J. L. Yuan and B. Sunden, J Electrochem Soc, 160, F1 (2013).

12. Y. Wang, H. Zhang, F. L. Chen and C. R. Xia, J Power Sources, 203, 34 (2012). 
13. J. H. Kim and H. Kim, Ceram Int, 38, 4669 (2012).

14. K. F. Chen, N. Ai, L. Zhao and S. P. Jiang, J Electrochem Soc, 160, F301 (2013).

15. F. Deganello, V. Esposito, M. Miyayama and E. Traversa, J Electrochem Soc, 154, A89 (2007).

16. Y. X. Zhang, Q. Sun, C. R. Xia and M. Ni, J Electrochem Soc, 160, F278 (2013).

17. H. Sumi, T. Yamaguchi, K. Hamamoto, T. Suzuki and Y. Fujishiro, J Power Sources, 226, 354 (2013).

18. R. Kiebach, C. Knofel, F. Bozza, T. Klemenso and C. Chatzichristodoulou, $J$ Power Sources, 228, 170 (2013).

19. S. R. Gandavarapu, K. Sabolsky, K. Gerdes and E. M. Sabolsky, Mater Lett, 95, 131 (2013).

20. Q. A. Li, L. P. Sun, L. H. Huo, H. Zhao and J. C. Grenier, J Power Sources, 196, 1712 (2011).

21. B. Huang, X. J. Zhu, Y. Lv and H. Liu, J Power Sources, 209, 209 (2012).

22. A. Faulkner-Jones, S. Greenhough, J. A. King, J. Gardner, A. Courtney and W. M. Shu, Biofabrication, 5 (2013).

23. S. Yamaguchi, A. Ueno, Y. Akiyama and K. Morishima, Biofabrication, 4 (2012).

24. K. S. Howe, A. R. Hanifi, K. Kendall, M. Zazulak, T. H. Etsell and P. Sarkar, Int J Hydrogen Energ, 38, 1058 (2013). 